\title{
Situando o Instituto \\ de Estudos Avançados Peter Wall
}

\author{
DIANNE NEWELL
}

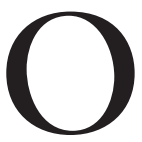

S Institutos de Estudos Avançados têm em comum a promoção de excelência acadêmica, conhecimento básico e ideias avançadas - e as expectativas para que todos esses objetivos sejam atingidos exigem tempo, requerem liberdade intelectual e exposição a riscos.

Para ser bem-sucedido, o IEA tem que enfrentar o desafio de manter tanto a integridade e a independência acadêmica quanto garantir o financiamento de base necessário para administrar e operar em longo prazo. O primeiro é muitas vezes mais difícil de cumprir para Institutos estabelecidos em Universidades, especialmente para os recém-criados, pois eles estão mais propensos do que os Institutos mais tradicionais a que se espere que sirvam como exemplos emblemáticos para suas Universidades anfitriãs.

A segurança financeira, entretanto, em geral é mais facilmente alcançada por meio da afiliação da entidade a uma Universidade, do que permanecendo como entidades totalmente independentes. Assim, estamos vendo mudanças: dois Institutos de Estudos Avançados antes independentes tornaram-se, de modo recente, por razões financeiras, ligados a Universidades: o Collegium Budapest - CEU Instituto de Estudos Avançados e o Center for Advanced Study in the Behavioral Sciences (Centro de Estudos Avançados em Ciências do Comportamento) em Stanford. De um modo ou de outro, a reputação acadêmica da maioria dos Institutos de Estudos Avançados parece se beneficiar da força da reputação da Universidade local e de seus estudiosos e centros de pesquisa, seja pela afiliação formal, como no caso do Radcliff Institute for Advanced Study (Instituto de Estudos Avançados Radcliff) em Harvard ou a Technical University of Munich-Institute for Advanced Study (Universidade Técnica de Munique - Instituto de Estudos Avançados), seja somente por uma questão de localização física (o Instituto de Estudos Avançados em Princeton vem à mente).

Enquanto a maioria dos Institutos de Estudos Avançados está estabelecida em Universidades, de um modo ou de outro, o Peter Wall Institute for Advanced Studies (Instituto de Estudos Avançados Peter Wall), localizado na Universidade de British Columbia, é um exemplo único de um Instituto universitário de Estudos Avançados inteiramente financiado por doação e por receber 
o nome de um benfeitor externo. É por certo admirável e algo especial que um empresário local tenha tido a visão de financiar um Instituto de Estudos Avançados. Mas, quaisquer que sejam os difíceis desafios para manter a integridade e independência para os IEA mencionados antes, sendo subordinados a um único doador (a Universidade de British Columbia também oferece uma doação, mas essa tem diminuído a ponto de financeiramente ter pouco impacto no funcionamento do Instituto Wall), eles apresentam seus próprios desafios em relação à independência.

Desde a sua fundação, em 1991, com uma grande doação de ações da Wall Financial Corporation estabelecida em Vancouver, a missão do Instituto tem sido a criação colaborativa, interdisciplinar, de programas de pesquisa básica para os acadêmicos da University of British Columbia (UBC) e equipes de pesquisa em todas as áreas e em todas as fases de suas carreiras. Uma grande parte das ideias e da pesquisa sobre a natureza dos Institutos de Estudos Avançados por parte da família do doador e da Universidade foi para o processo de planejamento do Wall Institute; o processo durou vários anos. Não antes de 1996, foi nomeado um diretor permanente, e só em 1999 o Instituto encontrou uma sede permanente para seus programas e eventos. Além de ser totalmente financiado por doação, o Instituto Wall é regido por um contrato de confiança e por seu próprio conselho de curadores, e guiado por um Comitê Consultivo Acadêmico. A partir dessa base de financiamento de dividendos periódicos sobre sua participação, afluíram espaços para o pensamento criativo e raras oportunidades para pesquisadores da UBC e acadêmicos visitantes que estão propensos a fazer descobertas intelectuais e científicas de longo prazo.

Como a maioria dos IEA, o Instituto Wall se esforça para ser tão diferente de uma Universidade assim como o é de Institutos de pesquisa especializados que povoam a Universidade. Com sua missão de promover o pensamento excelente, colaborativo, interdisciplinar e a pesquisa em várias disciplinas para acadêmicos em todas as áreas e em várias fases de suas carreiras, o Instituto Wall tornou-se um efetivo ímã para acadêmicos excelentes de toda a Universidade, e também internacionalmente para seus colegas que desejem compartilhar ideias e se engajar no livre pensar. Permanece até hoje o único Instituto no Canadá inspirado pelo Instituto de Estudos Avançados de Princeton, assim dedicado a reunir estudiosos para o livre exercício de aprendizado e pesquisa nos níveis mais altos.

No Instituto Wall, essas metas intelectuais são alcançadas por sua inspiradora localização e instalações e seus integrados programas de palestras, workshops exploratórios, séries de palestrantes, intercâmbios de parceria internacional e colóquios no exterior, e programas de residência para acadêmicos. Mediante eventos e oportunidades de pesquisa individuais e em grupos no Instituto, alianças estratégicas de curto prazo com iniciativas de pesquisa no campus e palestras públicas especiais oferecidas à comunidade maior, a novos grupos e a indivíduos 
na Universidade, o Instituto Wall tornou-se rapidamente o Instituto de pesquisa sênior na Universidade. A escala de seus programas é relativamente pequena, mas a intimidade como resultado parece ser um dos trunfos do Instituto Wall. Existem hoje milhares de pesquisadores de todo o mundo que participaram de eventos no Instituto Wall e perto de 400 professores associados da Universidade de British Columbia, acadêmicos que alcançaram esse status em virtude de serem Pesquisadores Principais de algum prêmio do Instituto Wall ou um membro de uma comissão do Instituto Wall.

No Instituto Wall, acredita-se que se possa ter a qualidade de diálogos necessária, de outro modo difícil de alcançar devido às exigências do mundo para a obtenção de resultados rápidos.

Os acadêmicos da Universidade de British Columbia que passam um ano no Instituto no âmbito do Programa Acadêmico Ilustre, por exemplo, elogiam o enorme valor do espaço físico, contemplativo e estimulante espaço que proporciona concentração em projetos de longo prazo e oportunidades para desenvolver relacionamentos, finalizar livros, realizar workshops, hospedar séries de palestrantes, escrever pesquisas e obter bolsas para ensino e aprendizagem, preparação de registros para patentes, produzir trabalhos artísticos e desenvolver novas colaborações de pesquisa e relacionamentos, entre outras coisas.

Muitas honrarias e distinções pessoais têm se originado, como se poderia esperar, dos programas residenciais do Instituto Wall, que são dirigidos a acadêmicos. Um ex-acadêmico ilustre em residência em ciência creditou ao Instituto Wall o apoio crítico necessário para finalizar um livro, The ecology of adaptive radiation [A ecologia da radiação adaptativa], com a Oxford University Press, que ele, de outra forma, nunca poderia ter concluído; a publicação acabou por ser o mais influente trabalho que ele já produziu, com mais de 1.500 citações ao longo dos anos. Outro estudioso sênior residente escreveu e publicou um artigo na Science com base no trabalho realizado no Instituto Wall, e também completou seu novo artigo, "Adaptive diversification" ["Diversificação adaptativa"], com a Princeton University Press. Essas importantes conquistas acadêmicas contribuíram para sua nomeação como membro da Sociedade Americana para o Avanço da Ciência. Há muitas histórias como essas, não somente no Instituto Wall, mas em todos os Institutos de Estudos Avançados, e a releitura deles aqui tem um efeito revigorante sobre as esperanças e os sonhos para o futuro de tais Institutos.

O Programa de Desenvolvimento de Tema do Instituto Wall, que patrocina workshops exploratórios curtos e de vários dias e equipes de pesquisa multidisciplinares por três anos, com frequência revela-se tão intelectualmente gratificante quanto nossos programas de residência, embora, como sempre, não seja esperado que todos os prêmios levem a avanços espetaculares ou pesquisas adicionais e honras. Mostra-se suficiente, no caso dos subsídios menores, ao explorar novos tópicos ou formar nova agenda de pesquisa. As expectativas são maiores em rela- 
ção aos workshops mais amplos e às bolsas para equipes de pesquisa com duração de mais de um ano letivo para pesquisadores da Universidade, que são exigidos a envolver, como participantes, pesquisadores de alto nível, externos à Universidade; além disso, espera-se que a Bolsa Temática Principal leve a Universidade de British Columbia a se tornar um centro de pesquisa sobre o tema da bolsa. Um pesquisador-chefe em uma premiação do Workshop Exploratório do Instituto Wall declarou como as ideias de pesquisa e de tema, que começaram com o recebimento do prêmio, constituíram-se em uma influência na formação de uma grande organização - a Canadian Prediction in Ungauged Basins (PUB) (Prognóstico Canadense em Bacias sem Sistema de Medição), e atividades relacionadas nacional e internacionalmente ao PUB, assim como a formação de uma nova rede de pesquisa de alta potência. As ideias formuladas no workshop culminaram, eventualmente, em uma importante descoberta e um artigo inovador que foi publicado no principal periódico da área de hidrologia. Outra pesquisadora observa que seu Seminário Exploratório com duração de três dias, "Arts-Based Methods in Health Research" ("Métodos fundamentados em Artes na Pesquisa em Saúde"), conduziu em dois anos a uma grande explosão de atividade acadêmica: uma bolsa do Canadian Institutes of Health Research (Institutos Canadenses de Pesquisa em Saúde) e do fundo UBC Teaching and Academic Growth (Ensino e Desenvolvimento Acadêmico da UBC), a preparação de três outras aplicações de bolsas, três publicações avaliadas por pares e um trabalho artístico, várias apresentações em conferências, e vários workshops e seminários.

Mesmo o prêmio Desenvolvimento de Tema, que simplesmente oferece almoço e o espaço de reunião por um dia para reunir pesquisadores da Universidade de British Columbia em torno de um tema, tem, de tempos em tempos, produzido resultados de material significativo: uma professora está, por exemplo, coeditando uma coleção de ensaios para um livro sobre a história de crianças e jovens; o desejo de produzir tal livro, ela relata, surgiu diretamente de discussões no workshop de Desenvolvimento de Tema do Instituto Wall com duração de um dia, do qual ela participou quando era uma Bolsista Iniciante dessa instituição. Os programas destinam-se a formar uma malha: para se candidatar a uma Bolsa Temática Principal do Instituto Wall, deve-se ter realizado um Workshop Exploratório do Wall, que pode, por sua vez, ter sido precedido pela obtenção de uma Bolsa de Desenvolvimento de Tema. Vários Bolsistas Iniciantes do Instituto Wall tornaram-se mais tarde, em suas carreiras, Acadêmicos Ilustres do Programa de Residência dessa instituição. Nem a temática, nem os programas de residência trabalham com tópicos predeterminados ou questões específicas em mente; ao contrário, os candidatos são livres para apresentar seus próprios temas, com a exigência de que seus projetos envolvam abordagens interdisciplinares. Essa prática "de baixo para cima" de conceder prêmios não é comum para a maioria dos Institutos de Estudos Avançados, mas se ajusta bem com o espírito do Instituto Peter Wall, com sua promessa de oferecer um lugar "onde as mentes convergentes explorem livremente". 
O Instituto Wall é único em outros importantes aspectos porque optou desde o início por renunciar ao usual (para os Institutos de Estudos Avançados) principal programa de convidar dezenas de ilustres acadêmicos de fora a passar um período de até um ano no Instituto. Em vez disso, o Instituto Wall se concentra em um conjunto integrado de programas temáticos e programas individuais para estudiosos da UBC e seus colegas internacionais. Nos últimos anos, tornamo-nos cada vez mais interessados em interagir mais formalmente com a comunidade internacional. Iniciamos, por exemplo, um programa modesto envolvendo em média por ano um professor visitante ilustre convidado a passar um breve, mas extremamente interativo, período no Instituto ministrando palestras, workshops e seminários, e interagindo com professores e estudantes de graduação interessados, em todo o campus e em centros fora do campus. Professores visitantes ilustres até a data incluem Dr. Arif Dirlik, historiador, Universidade Duke (que completou um livro no Instituto e conduziu um Curso de Verão do Wall sobre o Futuro da Sociedade Agrária que resultou em uma viagem de campo para a China e uma coleção de artigos editados); Dr. Roald Hoffman, ganhador do Prêmio Nobel em Química, Universidade Cornell (que, entre outras atividades, participou e apresentou palestras na British Columbia sobre o início de sua peça no teatro da Universidade); Dra. Barbara Grosz, Ciência da Computação e Decana, Instituto de Estudos Avançados Radcliffe de Harvard; do Collège de France, Paris, Dr. Alain Berthoz, Fisiologia (que está retornando ao Instituto durante um mês em 2011); Dr. Stanilas Dehaene, Psicologia Cognitiva Experimental; e Philippe Sansonetti, Microbiologia e Doenças Infecciosas.

A atual direção estratégica sobre a internacionalização do Instituto Wall é criar um pequeno número de significativas parcerias acadêmicas entre a rede internacional de Institutos de Estudos Avançados e instituições similares, a fim de colaborar e expandir nossos esforços mútuos de descoberta e esclarecimento. O Instituto estabeleceu parcerias dinâmicas com um dos precursores de todos os IEA, o Collège de France, estabelecido em 1530, e também com um dos mais novos, a Universidade Técnica de Munique - IEA, fundado em 2005. O Instituto Wall serviu como uma referência para os planejadores do TUM-IEA e é representado no seu Conselho de Curadores internacionais. O Instituto Wall tem também uma parceria com o único Instituto de Estudos Avançados da África, Stias, em Stellenbosch, África do Sul, fundado há uma década.

De acordo com os acordos renováveis a cada quatro anos com os nossos parceiros internacionais, o Instituto está apto a acolher, a cada ano, vários excelentes professores do Collège de France, no contexto de seu programa de convidados de professor visitante ilustre do Wall, e, por sua vez, o Collège pode receber indicações de até três professores associados seniores do Instituto por um mês sob a rubrica de seu programa de Intercâmbio Internacional. O Instituto Stellenbosch nomeará até cinco professores associados seniores do Instituto Wall para bolsas de três meses ou mais. O acordo do Instituto Wall com TUM- 
IEA facilita os intercâmbios breves anuais de pequenos grupos de pesquisa interdisciplinar com interesses em um tema comum. Nos últimos três anos, aconteceram três intercâmbios recíprocos de professores seniores do Peter Wall e do Collège de France, e dois professores associados do Wall utilizaram seis meses de bolsas no Stias.

Todas as três instituições parceiras internacionais nos últimos três anos copatrocinaram e hospedaram os Colóquios Peter Wall no exterior. Os Colóquios no exterior representam um programa novo e exclusivo direcionado especificamente a reforçar as relações com nossos parceiros internacionais, aumentando a reputação internacional do Instituto Wall, e expandindo as oportunidades de colaboração de pesquisa internacional para professores associados do Instituto. Tal como os Workshops Exploratórios do Wall realizados no Instituto, os Colóquios Peter Wall no exterior são reuniões internacionais dirigidas por professores associados do Instituto Wall para as quais os estudiosos de diversas disciplinas, a partir da UBC e do exterior, se reúnam por um período de dois a quatro dias para desenvolver novas agendas de pesquisas sobre temas de ponta. A realização de reuniões do Instituto Wall em Institutos de outras partes do mundo tanto criou mais duradouras conexões institucionais quanto possibilitou a participação aos pesquisadores líderes, os quais, de outro modo, poderiam não ser capazes de fazê-lo. A importância dos temas para esses colóquios internacionais e interdisciplinares é evidente a partir de seus títulos: "Coerência e incoerência em temperaturas ultrafrias", "Biônicos multimodais e sensório-motores", "Muitas vozes, uma canção: escolas promotoras de saúde: evidência, estratégias, desafios e perspectivas", "A criança exposta ao HIV: como morbidade e mortalidade excessivas podem ser explicadas?", "Microbiota comensal: da homeóstase à doença", "Continuidade em regime de energia: falha de transição e a persistência da sustentabilidade (discutindo a situação energética na Europa ao longo de um período de 400 anos)" e "O papel das proteínas de junção gap na saúde e na doença" (previsto para 2012).

Uma segunda nova direção estratégica para o Instituto Wall tem um objetivo bem diferente: alcançar a comunidade da Grande Vancouver com uma nova série de palestras públicas no centro da cidade, chamada Intercâmbio Wall, que traz escritores proeminentes, pesquisadores e humanistas a Vancouver. Convidando o público para "Juntar-se ao debate", o Intercâmbio Wall foi planejado como um programa de comunidade para oferecer um fórum público à discussão das principais questões que afetam a todos nós, incluindo, por exemplo, a genonomia, a segurança global e crianças em risco. Os eventos devem ser realizados a cada ano na primavera e outono e se destinam a apresentar uma figura pública renomada que tenha contribuído com novos conhecimentos para as Artes, as Ciências ou as Humanas.

A abertura da série do Intercâmbio Wall, em maio de 2011, foi uma noite com o pesquisador pioneiro científico norte-americano, e uma das pessoas mais 
influentes do mundo, J. Craig Venter, sequenciador do genoma humano. Venter envolveu uma audiência de mais de mil pessoas, incluindo centenas de jovens, em uma palestra ilustrada sobre seus novos esforços de pesquisa: a construção da primeira célula sintética e a expedição de amostragem global de oceano - sequenciamento e análise do DNA dos micro-organismos que vivem nessas águas. O Intercâmbio Wall para o outono de 2011 apresenta Derek Gregory, um famoso geógrafo político que é também o recém-nomeado professor ilustre do Peter Wall. Gregory falou sobre "A guerra em toda parte" - guerras conduzidas nas sombras do 11 de Setembro que têm muito a nos dizer sobre o futuro da violência, da segurança e da vida cotidiana. Segundo Gregory, o que ele chama de "guerra em toda a parte" mudou a natureza da guerra no início do século XXI. O espaço de matar ainda tem uma intimidade terrível, mas agora vivemos em um mundo onde a morte pode ser entregue em grandes distâncias, e sucessivas administrações americanas especulam abertamente sobre como conduzir a "guerra em países com os quais não estamos em guerra". Tudo isso faz que seja difícil ver onde termina a guerra e começa a paz.

Ao concluir, é importante pelo menos, mencionar a importância da qualidade das instalações para o trabalho e o sucesso do Instituto Wall e de todos os outros Institutos de Estudos Avançados. De modo a se transferir para suas novas permanentes instalações no Leon \& Thea Koerner University Centre, o anterior Clube de Professores da UBC, em 1999, o Instituto se envolveu em extensas reformas para criar salas de conferências e para outras reuniões, escritórios para acadêmicos, e acomodações para pesquisadores visitantes. Grandes e pequenas reformas vêm acontecendo desde então, tanto para melhorar o conforto quanto para acomodar mudanças nos programas do Instituto. As instalações de conferência do Instituto estão disponíveis para a comunidade universitária para eventos de pesquisas relacionadas, que atraem muitas pessoas e grupos ao Instituto Wall que de outro modo não poderiam tomar conhecimento sobre os programas e eventos. Trata-se de uma grande vantagem para o Instituto estar localizado na Universidade de British Columbia, classificada por pesquisas internacionais entre as melhores Universidades de pesquisas do mundo, e no local mais privilegiado no campus da Universidade: no coração cultural do ambiente e com vista para o mar e para a cadeia de montanhas costeiras. A localização privilegiada da Universidade encontra-se em Vancouver, que é em si mesma repetidamente citada como uma das cidades mais vibrantes do mundo.

Independentemente da atratividade de suas instalações e de seu entorno, claro, no final, é a qualidade dos indivíduos que se envolvem com o Instituto Wall, e dos processos de adjudicação e as comissões que se dedicam a selecionálos, que cria o tipo de Instituto de Estudos Avançados que a maior parte desses Institutos empenha-se em se tornar. No Instituto Wall, um comitê único e multidisciplinar avalia aplicações para cada programa, independentemente das disciplinas de origem dos candidatos: os físicos teóricos leem propostas de especia- 
listas de literatura inglesa; cientistas políticos avaliam cientistas da computação. Tudo isso parece funcionar. As decisões finais de cada comissão de programa, presididas em todos os casos pelo diretor do Instituto, são alcançadas de forma colaborativa e por unanimidade. $\mathrm{O}$ aspecto mais difícil do processo de avaliação parece ser o mesmo que talvez todos nós tenhamos que lidar em Institutos de Estudos Avançados em todos os lugares: normas. Como se pode lutar pelos mais altos padrões de excelência acadêmica, quando também se enfrentam pressões para operar com equanimidade? Essa questão das normas se constitui, ao menos para o Instituto Wall - como todos os nossos outros debates -, contínua.

Dianne Newell é professora e diretora do Instituto Peter Wall de Estudos Avançados, Universidade de British Columbia. @ - dianne.newell@pwias.ubc.ca

Tradução de Valéria Wasserman. O original em inglês - "Where Converging Mentes Freely Explore: Lacating the Peter Wall Institute for Advanced Studies" - encontra-se à disposição do leitor no IEA-USP para eventual consulta.

Recebido em 13.9.2011 e aceito em 22.9.2011. 